\title{
Tocopherols and phytosterols in sunflower seeds for the human food market
}

\author{
By A. Fernández-Cuesta ${ }^{a}$, A. Nabloussi ${ }^{b}$, J.M. Fernández-Martínez ${ }^{a}$ and L. Velasco ${ }^{a, *}$ \\ ${ }^{a}$ Instituto de Agricultura Sostenible (IAS-CSIC). Alameda del Obispo s/n, 14004 Córdoba, Spain \\ ${ }^{b}$ INRA-CRRA. P.O. Box 578, 50000 Meknès, Morocco \\ *Corresponding author: Ivelasco@ias.csic.es
}

\section{RESUMEN}

Tocoferoles y fitoesteroles en semillas de girasol para consumo directo.

Las semillas de girasol para consumo directo proceden tanto de cultivares oleaginosos, con aquenios negros y baja proporción de cáscara, como de cultivares de consumo directo, con aquenios de colores claros o rayados y elevada proporción de cáscara. El objetivo de este trabajo fue evaluar el contenido en tocoferoles y fitoesteroles en semillas de ambos tipos de cultivares. Se evaluaron cinco cultivares oleaginosos y siete cultivares de consumo directo en ensayos de campo replicados en dos localidades de Marruecos y España. Se identificó gran variación para peso de 100 semillas (aquenios descascarillados; 2.6 a $5.5 \mathrm{~g}$ ), contenido en aceite en la semilla (42.7 a $67.5 \%$ ), contenido en tocoferoles (203 a $397 \mathrm{mg} \mathrm{kg}^{-1}$ semilla), y contenido en fitoesteroles (2179 a $3555 \mathrm{mg} \mathrm{kg}^{-1}$ semilla). No se observaron diferencias entre ambos tipos de cultivares para peso de semilla, contenido de aceite en la semilla, o perfiles de tocoferoles y fitoesteroles. Sin embargo, los cultivares oleaginosos presentaron mayor contenido medio de tocoferoles y fitoesteroles, aunque se identificaron cultivares de consumo directo con niveles de estos compuestos similares a los mejores cultivares oleaginosos. La gran variación encontrada para contenido en tocoferoles y fitoesteroles sugiere la posibilidad de elevar los niveles de estos compuestos mediante mejora genética con el objetivo de desarrollar cultivares de girasol de consumo directo más saludables.

PALABRAS CLAVE: Contenido en aceite - Fitoesteroles - Girasol de consumo directo - Girasol oleaginoso - Tocoferoles - Variabilidad.

\section{SUMMARY}

Tocopherols and phytosterols in sunflower seeds for the human food market.

Sunflower seeds for the human food market are derived from both oilseed-type cultivars, with black achenes and low hull proportion, and confectionery-type cultivars, with striped achenes and high hull proportion. The objective of this research was to evaluate tocopherol and phytosterol contents in the seeds of both types of cultivars. Five oilseed-type and seven confectionery-type cultivars were evaluated in replicated field trials in two locations of Morocco and Spain. Large variations were found in hundred-kernel weight (2.6 to $5.5 \mathrm{~g}$ ), kernel oil content (42.7 to $67.5 \%$ ), tocopherol content (203 to $397 \mathrm{mg} \mathrm{kg}^{-1}$ kernel), and phytosterol content (2179 to $3555 \mathrm{mg} \mathrm{kg}^{-1}$ kernel). Both types of cultivars did not differ for kernel weight, kernel oil content, or tocopherol and phytosterol profiles. However, oilseed-type cultivars had significantly greater average tocopherol and phytosterol contents, though confectionery-type cultivars with levels of tocopherols and phytosterols similar to the best oilseed-type cultivars were identified. The large variations in kernel tocopherol and phytosterol contents found in this research suggest that there is room for breeding for increased levels of these compounds in order to develop healthier sunflower cultivars for the human food market.

KEY-WORDS: Confectionery sunflower - Oil content Oilseed sunflower - Phytosterols - Tocopherols - Variability.

\section{INTRODUCTION}

More than thirty million tones of sunflower seeds (intact achenes) are produced annually in the world. From these, around $90 \%$ are crushed to produce sunflower oil, whereas the remaining $10 \%$ are used for non-oil purposes (National Sunflower Association, 2011). Sunflower seeds entering the non-oil markets, also known as confectionery or confection seeds, are generally produced from specific confectionery-type cultivars characterized by large achenes that are black (or grey) and white striped and contain a high hull percentage. Seeds from oilseed-type cultivars that produce smaller black achenes with low hull content (FernándezMartínez et al., 2009) are also destined for the food market in some areas. Countries such as US, Spain, Turkey and China mainly demand confectionery-type seeds for the food market (Lofgren, 1997; Kaya, 2004; Zhang, 2004); although customers in other areas such as the Balkan region and Morocco prefer oilseed-type seeds (Kaya, 2004; El Asri et al., 2006). In the US, seeds from confectionery cultivars are separated into three grades based on size. The largest seeds $(>7.9 \mathrm{~mm})$, called "in-shell seeds", are marketed unhulled, salted and roasted to be consumed as a snack food. Medium-size seeds (>7.1 mm), called "hulling seeds" are hulled and the kernels are used, either roasted or not, as a snack food or in a number or confectionery or bakery products. Finally, smaller seeds $(<7.1 \mathrm{~mm})$, called "bird seeds", are mainly intended for feeding wild birds and pets (Lofgren, 1997).

Sunflower seeds are regarded as a healthy food (Lloyd-Williams et al., 2008). They are one of the 
richest food sources of vitamin $E$ in the form of $\alpha$-tocopherol (Izquierdo et al., 2007; U.S. Department of Agriculture, 2011). They are also a rich source of phytosterols (Phillips et al., 2005). However, little is known on the variation for these traits among cultivars used for food. The objective of this research was to evaluate the tocopherol and phytosterol contents in seeds from sunflower cultivars used for food, both of the oilseed type and the confectionery type.

\section{MATERIALS AND METHODS}

\subsection{Plant materials and cultivation}

The study was based on five oilseed-type cultivars widely used for food in Morocco and seven confectionery-type cultivars. Oilseed-type cultivars from Morocco were Karima, Oukrania, Peredovik, Salima, and Znatia. Karima and Salima were released by INRA-Morocco (Nabloussi et al., 2005). Peredovik is an old Russian cultivar widely cultivated in Morocco. Oukrania and Znatia are local varieties collected from the Kenitra province (34 $\left.31^{\prime} 31^{\prime \prime} \mathrm{N}, 06^{\circ} 19^{\prime} 12^{\prime \prime} \mathrm{W}\right)$. Confectionery-type cultivars included six landraces collected from farmers' fields in Spain and cultivar MK-1, collected from the Larache province in Morocco (35 $15^{\circ} 60^{\prime \prime} \mathrm{N}$, $\left.06^{\circ} 09^{\prime} 00^{\prime \prime} \mathrm{W}\right)$. The Spanish landraces collected from the province of Córdoba include: B-2, (37 $16^{\prime} 09^{\prime \prime} \mathrm{N}$,

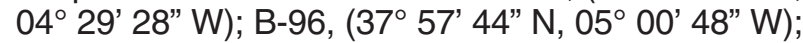
B-107, (37 $\left.28^{\circ} 16^{\prime \prime} \mathrm{N}, 04^{\circ} 34^{\prime} 16^{\prime \prime} \mathrm{W}\right)$. B-132, was collected from the province of Jaen (38 $10^{\prime} 09^{\prime \prime} \mathrm{N}$, $\left.02^{\circ} 58^{\prime} 37^{\prime \prime} \mathrm{W}\right)$; B-146 was collected from the province of Granada ( $37^{\circ} 26^{\prime} 04^{\prime \prime}$ N, $\left.03^{\circ} 40^{\prime} 21^{\prime \prime} \mathrm{W}\right)$; and B-307 was collected from the province of Cuenca (40 $\left.07^{\prime} 17^{\prime \prime} \mathrm{N}, 02^{\circ} 54^{\prime} 53^{\prime \prime} \mathrm{W}\right)$. All the cultivars are open pollinated with a high degree of self-incompatibility.

Plants of the 12 cultivars were grown in the field in 2009 in the experimental farm of the Instituto de Agricultura Sostenible at Córdoba, Spain, and the experimental farm of the Institut National de la Recherche Agronomique at AïnTaoujdate, Morocco. The plants were grown in a replicate trial with three replicates each consisting of four rows, $5-\mathrm{m}$ long, with $60-\mathrm{cm}$ spacing between rows. The heads of 12 plants of the two central rows were bagged with mesh bags after flowering to protect them from bird damage. Individual plants were harvested at maturity. Seed quality traits were analyzed at the single-plant level.

\subsection{Analysis of oil content}

Fifty achenes per head were randomly chosen and desiccated for $2 \mathrm{~h}$ at $105^{\circ} \mathrm{C}$ in a convection oven, then maintained in a desiccator for $1 \mathrm{hr}$. Desiccated achenes were weighed and their oil content was measured by nuclear magnetic resonance (NMR) on an Oxford 4000 analyzer (Oxford Analytical Instruments Ltd., Abingdon, OX,
UK). The achenes were then hulled and the hull proportion and hundred-kernel weight were measured. Kernel oil content was calculated from achene oil content and hull proportion.

\subsection{Chemical reagents, standards, columns, and instrumental equipment}

Iso-octane of HPLC quality (Cat. No. 362064.1612), hexane for analysis (Cat. No. 361347.1612), n-heptane for analysis (Cat. No. 122062.1612), potassium hydroxide $85 \%$ pellets for analysis (Cat. No. 121515.1210), and a silylating mixture composed of pyridine:hexamethyldisilazane:trimeth ylchlorosilane 9:3:1 by vol (Cat. No. 355650.0922) were purchased from Panreac Química, S.A.U., Barcelona, Spain. Tert-butyl methyl ether of HPLC quality (Cat. No. 1.01845.2500) was purchased from Merck KGaA, Darmstadt, Germany. Ethanol absolute (Cat. No. 8006) was purchased from J.T. Baker (Deventer, The Netherlands).

Tocopherol standards (Calbiochem Tocopherol Set, Cat. No. 613424) were purchased from Merck. Cholesterol of $99 \%$ purity (Cat. No. C8667) was purchased from Sigma-Aldrich (St. Louis, MO, USA).

The column used for high performance liquid chromatography (HPLC) analyses was a LiChrospher 100 diol $250 \mathrm{~mm} \times 3 \mathrm{~mm}$ I.D. with $5-\mu \mathrm{m}$ spherical particles (Cat. No. 1.50177.7075), connected to a silica guard column LiChrospher Si $60,4 \mathrm{~mm} \times 4 \mathrm{~mm}$ I.D. (Cat. No. 1.50955.0001), both of them purchased from Merck. The column used for gas chromatographic (GC) analyses was a ZB-5 capillary column (id $=0.25 \mathrm{~mm}$, length $=30$ $\mathrm{m}$, film thickness $=0.10 \mu \mathrm{m}$ ) purchased from Phenomenex, Torrance, CA, USA.

Centrifugation was conducted using the equipment Unicen 21 from Ortoalresa, Madrid, Spain. Sample crushing and homogenization were conducted with a homogenizer Heidolph RC 500, Kelheim, Germany. GLC analyses were conducted on a Perkin Elmer Clarus 600 GC (Perkin Elmer Inc, Waltham, MA, USA). HPLC equipment consisted of a pump model 515, a fluorescence detector model 2475, and an autosampler model 717 plus, all of them from Waters Corporation, Milford, MA, USA.

\subsection{Analysis of tocopherol content}

Six randomly selected achenes from each single plant were husked, weighed and crushed as fine as possible with a stainless steel rod. Tocopherol extraction, separation by HPLC, and quantification were conducted following the procedures described by Goffman et al. (1999) using a fluorescence detector at $295 \mathrm{~nm}$ excitation and $330 \mathrm{~nm}$ emission and iso-octane/tert-butylmethylether (94:6) as eluent at an isocratic flow rate of $0.8 \mathrm{mLmin}^{-1}$. A quantitative determination of tocopherols was done by using external calibration curves obtained for 
each of the tocopherol homologues $\alpha-, \beta-$, and $\gamma$-tocopherol using tocopherol standards. Total tocopherol content was calculated as the sum of $\alpha-$, $\beta$-, and $\gamma$-tocopherol contents and expressed as mg $\mathrm{kg}^{-1}$ kernel.

\subsection{Analysis of phytosterol content}

Phytosterol content was determined following a previously reported procedure (Fernández-Cuesta et al., 2012). Six seed kernels per plant were placed in $10-\mathrm{mL}$ propylene tubes. Two-hundred $\mu \mathrm{L}$ of internal standard solution prepared by dissolving cholesterol in a hexane-ethanol (3:2) solution at a concentration of $0.1 \%$ were added. Alkaline hydrolysis was performed by adding $2 \mathrm{~mL}$ of a solution of potassium hydroxide dissolved in ethanol at a concentration of $2 \%$. Seeds were crushed and homogenized in a homogenizer equipped with a stainless-steel rod of $8 \mathrm{~mm}$ diameter at a speed of $5.000 \mathrm{rpm}$ for about $15 \mathrm{sec}$. Seed rests in the rod were washed with $1 \mathrm{~mL}$ of the ethanolic solution of potassium hydroxide and collected in the tube. The tubes were then left in a water bath at $80^{\circ} \mathrm{C}$ for $15 \mathrm{~min}$. Phytosterols were extracted by vortexing with $1 \mathrm{~mL}$ hexane and 1.5 $\mathrm{mL}$ water. The upper hexane layer was transferred to 2-mL glass vials that were kept in an oven at $37.5^{\circ} \mathrm{C}$ overnight. Fifty $\mu \mathrm{L}$ of hexane and $50 \mu \mathrm{L}$ of silylating mixture were added to the dried pellets and the vials were left at room temperature for 15 min. The solution was transferred to $2-\mathrm{mL}$ vials containing $200 \mu \mathrm{L}$ inserts and centrifuged at 4.000 $\mathrm{rpm}$ for $10 \mathrm{~min}$. The vials were capped and stored at $-20^{\circ} \mathrm{C}$ until analysis, usually within $24 \mathrm{~h}$ of preparation. Gas chromatographic analyses were performed using hydrogen as carrier gas at a pressure of $125 \mathrm{KPa}$. The Split injector and flame ionization detector were maintained at $320^{\circ} \mathrm{C}$. The oven thermal regime was the following: initial temperature of $240^{\circ} \mathrm{C}$ was increased at $5^{\circ} \mathrm{C} \mathrm{min}{ }^{-1}$ to a final temperature of $265^{\circ} \mathrm{C}$ and held for $10 \mathrm{~min}$. Total analytical time was $15 \mathrm{~min}$. Total phytosterol content was calculated as the sum of individual phytosterols and expressed as $\mathrm{mg} \mathrm{kg}^{-1}$ kernel. A chromatogram of phytosterol separation using this method is shown in Figure 1.

\subsection{Statistical analysis}

Data were analyzed according to the General Linear Model procedure of IBM SPSS Statistics version 19.0 (IBM Corp., Armonk, NY, USA). Analysis of variance was performed with genotypes as the fixed factor and location as the random factor. The comparison of means was performed by independent t-tests.

\section{RESULTS AND DISCUSSION}

\subsection{Analysis of variance}

The analysis of variance showed that variation in hundred-kernel weight was mainly associated with the effect of locations, with no significant effect of genotypes or genotype $\times$ location interaction (Table 1). Previous studies have focused on the study of the heritability of achene weight (Miller and Fick, 1997; Fernández-Martínez et al., 2009), but to our knowledge there is no information on the influence of genetic and environmental factors on the kernel weight of sunflowers. The main factor explaining the observed variation in kernel oil content was the genotype $\times$ location interaction, with no significant contribution of genotypes or locations (Table 1).

Variation in kernel tocopherol content was mainly explained by the effect of genotypes and the interaction genotype $\times$ location (Table 1 ). This is in agreement with a previous study on sunflower commercial hybrids (Velasco et al., 2002).

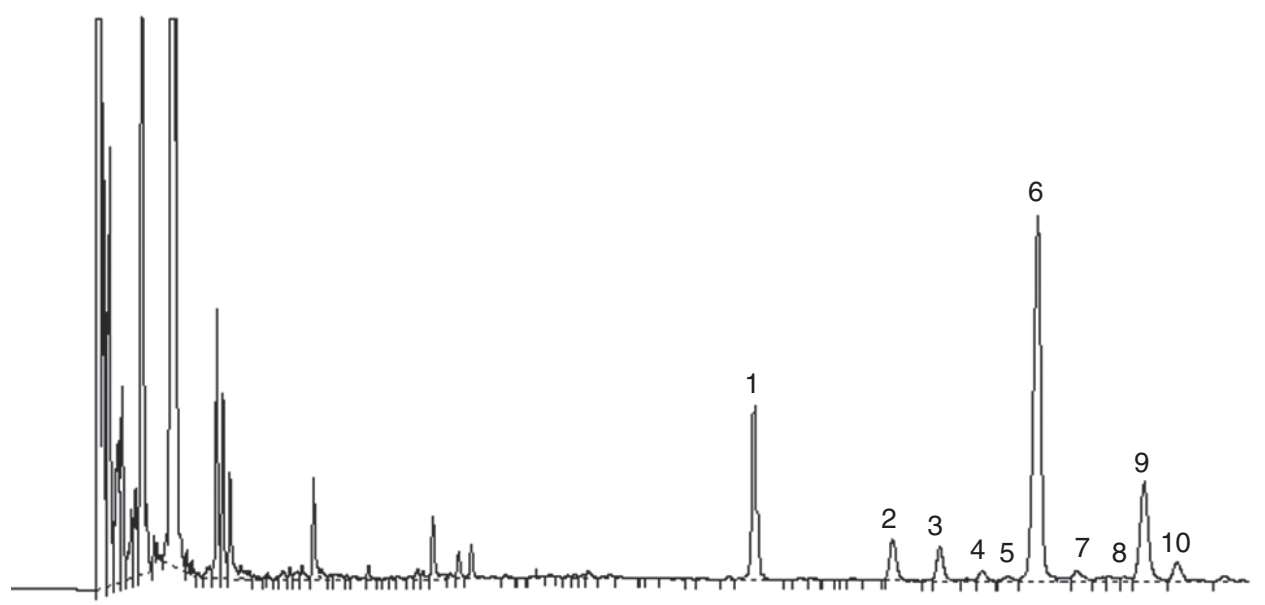

Figure 1

Chromatogram of phytosterols in a sample of six sunflower seeds (husked achenes) $1=$ Cholesterol (internal standard); $2=$ Campesterol; $3=$ Stigmasterol; $4=\Delta^{7}$-Campesterol; $5=$ Clerosterol; $6=\beta$-Sitosterol; $7=\Delta^{5}$-avenasterol; $8=\Delta^{5,24}$-Stigmastadienol; $9=\Delta^{7}$-Stigmastenol; $10=\Delta^{7}$-Avenasterol. Analysis time $=15 \mathrm{~min}$. 
Table 1

Analysis of variance (mean squares) for hundred-kernel weight (HKW), kernel oil content (KOC), total tocopherol (T) content and proportion of individual tocopherols in 12 sunflower cultivars grown in Córdoba, Spain and AïnTaoujdate, Morocco in 2009

\begin{tabular}{lrrrrrr}
\hline & DF $^{\mathrm{a}}$ & HKW (g) & KOC (\%) & $\begin{array}{c}\text { Total-tocopherols } \\
\left(\mathbf{m g ~ k g}^{-1}\right)\end{array}$ & $\alpha-\mathbf{T}(\%)$ & $\beta-T(\%)$ \\
\hline Genotype (G) & 11 & $3.6 \mathrm{~ns}^{\mathrm{b}}$ & $663.1 \mathrm{~ns}$ & $64269.4^{*}$ & $8.2^{*}$ & $7.3^{*}$ \\
Location (L) & 1 & $98.3^{* *}$ & $1749.3 \mathrm{~ns}$ & $19688.2 \mathrm{~ns}$ & $32.0^{* *}$ & $17.6^{*}$ \\
$\mathrm{G} \times \mathrm{L}$ & 8 & $3.7 \mathrm{~ns}$ & $615.0^{* *}$ & $18581.7^{* *}$ & $1.8 \mathrm{~ns}$ & $1.9 \mathrm{~ns}$ \\
\hline
\end{tabular}

${ }^{a} \mathrm{DF}$, degree of freedom; ${ }^{\mathrm{b} * *},{ }^{*}$ : significant at the $1 \%$ and $5 \%$ probability levels, respectively; ns: not significant.

Genotype $\times$ location interaction did not influence the proportion of $\alpha$ - and $\beta$-tocopherol, for which the location and to a lesser extent the genotype effect were predominant. Finally, variation in kernel phytosterol content was mainly attributable to the effect of the location and the interaction of genotype $\times$ location (Table 2 ). A study on soybean concluded that phytosterol content in the extracted oil was influenced by both the genotype and the planting location, as well as by their interaction (Vlahakis and Hazebroek, 2000). The latter was also the main factor explaining the proportion of most of the major phytosterols in the present study, i.e. campesterol, $\beta$-sitosterol, $\Delta^{7}$-stigmastenol, and $\Delta^{7}$-avenasterol. Conversely, the proportion of stigmasterol was mainly influenced by the location effect (Table 2).

\subsection{Variation in kernel weight and kernel oil content}

The average hundred-kernel weight ranged from 4.4 to $5.5 \mathrm{~g}$ in Spain and from 2.6 to $4.5 \mathrm{~g}$ in Morocco (Table 3). Kernel oil content ranged from 49.4 to $54.2 \%$ in Spain and from 42.7 to $67.5 \%$ in Morocco. It is interesting to note that neither hundred-kernel weight nor kernel oil content were significantly different between confectionery-type (B-2, B-96, B-107, B-132, B-146, B-307, and MK-1) and oilseedtype cultivars (Karima, Oukrania, Peredovik, Salima, Znatia). The hundred-kernel weight in Spain averaged $5.1 \mathrm{~g}$ for confectionery-type cultivars and $4.8 \mathrm{~g}$ for oilseed-type cultivars $(\mathrm{t}=1.3$; $\mathrm{P}>0.05)$, whereas kernel oil content averaged $51.7 \%$ for confectionery-type cultivars and $52.0 \%$ for oilseed- type cultivars ( $t=-0.6 ; \mathrm{P}>0.05$ ). Similarly, the hundred-kernel weight in Morocco averaged $3.7 \mathrm{~g}$ for confectionery-type cultivars and $4.0 \mathrm{~g}$ for oilseedtype cultivars ( $\mathrm{t}=-1.4 ; \mathrm{P}>0.05)$, whereas the kernel oil content averaged $56.8 \%$ for confectionerytype cultivars and $55.1 \%$ for oilseed-type cultivars $(t=1.0 ; P>0.05)$. Oilseed-type and confectionerytype sunflower cultivars differ for achene oil content and proportion of hull (Fernández-Martínez et al., 2009), but the kernels of confectionery-type sunflowers possess a high oil content similar to oilseed-type sunflowers (Buendia and D'Appolonia, 1986), which was confirmed in the cultivars evaluated in the present research.

\subsection{Variation for tocopherol content}

Average kernel tocopherol content ranged from 241 to $363 \mathrm{mg} \mathrm{kg}^{-1}$ in plants grown in Spain and from 203 to $397 \mathrm{mg} \mathrm{kg}^{-1}$ in plants grown in Morocco (Table 3). These tocopherol levels are within the range of variation reported in a large germplasm collection of sunflower, from 119 to $491 \mathrm{mg} \mathrm{kg}^{-1}$ seed kernel (Velasco et al., 2010). $\alpha$-tocopherol was in all cases the predominant tocopherol form accounting in all cases for more than $96 \%$ of the total tocopherols, which is the typical tocopherol profile in sunflower except for breeding material in which alternative tocopherol profiles have been developed (Fernández-Martínez et al., 2009). Oilseed-type cultivars averaged higher tocopherol contents than confectionery-type cultivars in both environments (Spain: $\mathrm{t}=-2.16, \mathrm{P}<0.05$; Morocco: $\mathrm{t}=-2.92, \mathrm{P}<0.01)$. However, confectionery-type cultivars having similar tocopherol contents as the

Table 2

Analysis of variance (mean squares) for total kernel phytosterol content and proportion of individual phytosterols in 12 sunflower cultivars grown in Córdoba, Spain and AïnTaoujdate, Morocco in 2009

\begin{tabular}{lccccccc}
\hline \multicolumn{7}{c}{} & \multicolumn{7}{c}{ Sterol composition (\%) } \\
& DF $^{\text {a }}$ & $\begin{array}{c}\text { Total sterols } \\
\left(\mathbf{m g ~ k g}^{-1}\right)\end{array}$ & Campesterol & Stigmasterol & $\begin{array}{c}\beta- \\
\text { Sitosterol }\end{array}$ & $\begin{array}{c}\Delta^{7} \text { - } \\
\text { Stigmastenol }\end{array}$ & $\begin{array}{c}\Delta^{7} \text { - } \\
\text { Avenasterol }\end{array}$ \\
\hline Genotype (G) & 11 & $1923424 \mathrm{~ns}^{\mathrm{b}}$ & $29.4 \mathrm{~ns}$ & $9.1 \mathrm{~ns}$ & $79.1 \mathrm{~ns}$ & $68.3 \mathrm{~ns}$ & $4.1 \mathrm{~ns}$ \\
Location (L) & 1 & $11757132^{*}$ & $63.7 \mathrm{~ns}$ & $112.9^{* *}$ & $287.3 \mathrm{~ns}$ & $15.7 \mathrm{~ns}$ & $2.5 \mathrm{~ns}$ \\
$\mathrm{G} \times \mathrm{L}$ & 8 & $1092966^{* *}$ & $13.5^{* *}$ & $5.1 \mathrm{~ns}$ & $229.9^{* *}$ & $226.9^{* *}$ & $5.5^{* *}$ \\
\hline
\end{tabular}

${ }^{a} \mathrm{DF}$, degree of freedom; ${ }^{\mathrm{b} \star},{ }^{\star}:$ : significant at the $1 \%$ and $5 \%$ probability levels, respectively; ns: not significant. 
Table 3

Mean values for hundred-kernel weight (HKW), kernel oil content (KOC), total kernel tocopherol (T) content and proportion of individual tocopherols in 12 sunflower cultivars grown in Córdoba, Spain and AïnTaoujdate, Morocco in 2009.

\begin{tabular}{|c|c|c|c|c|c|c|c|c|c|c|}
\hline \multirow[b]{2}{*}{ Cultivar } & \multicolumn{5}{|c|}{ Córdoba, Spain } & \multicolumn{5}{|c|}{ Aïn Taoujdate, Morocco } \\
\hline & $\begin{array}{c}\text { HKW }^{\mathrm{a}} \\
(\mathrm{g})\end{array}$ & $\begin{array}{c}\text { KOC } \\
(\%)\end{array}$ & $\begin{array}{c}\text { Total } \\
\begin{array}{c}\text { Tocopherol } \\
\left(\mathrm{mg} \mathrm{kg}^{-1}\right)\end{array} \\
\end{array}$ & $\begin{array}{l}\alpha-T \\
(\%)\end{array}$ & $\begin{array}{l}\beta-T \\
(\%)\end{array}$ & $\begin{array}{c}\text { HKW } \\
\text { (g) }\end{array}$ & $\begin{array}{c}\text { KOC } \\
(\%)\end{array}$ & $\begin{array}{c}\text { Total } \\
\text { Tocopherol }^{\text {to }} \\
\left(\mathrm{mg} \mathrm{kg}^{-1}\right)\end{array}$ & $\begin{array}{l}\alpha-T \\
(\%)\end{array}$ & $\begin{array}{l}\beta-T \\
(\%)\end{array}$ \\
\hline B-2 & - & - & - & - & - & $3.8^{b}$ & $42.7^{a}$ & $349^{b c}$ & $97.8^{b c}$ & $2.2^{a b}$ \\
\hline B-96 & $4.8^{a}$ & $50.8^{a b c}$ & $241^{a}$ & $97.9^{d}$ & $2.0^{a}$ & $2.6^{a}$ & $62.5^{\text {def }}$ & $203^{a}$ & $99.0^{c}$ & $1.0^{a}$ \\
\hline B-107 & $5.5^{a}$ & $50.2^{a b}$ & $347^{c d}$ & $96.5^{a}$ & $3.3^{d e}$ & $3.5^{a b}$ & $57.9^{d}$ & $397^{c}$ & $97.4^{a b}$ & $2.5^{a b c}$ \\
\hline B-132 & - & - & - & - & - & $4.0^{b}$ & $58.7^{d}$ & $327^{b}$ & $96.2^{a}$ & $3.8^{c}$ \\
\hline B-146 & $5.1^{a}$ & $53.4^{c d}$ & $271^{a b}$ & $97.4^{c d}$ & $2.5^{a b c}$ & - & - & - & - & - \\
\hline B-307 & $4.9^{a}$ & $49.4^{a}$ & $280^{a b}$ & $97.5^{c d}$ & $2.2^{a b}$ & $3.9^{b}$ & $51.3^{c}$ & $326^{b}$ & $97.9^{b c}$ & $2.1^{a b}$ \\
\hline MK-1 & $5.0^{a}$ & $54.2^{d}$ & $311^{b c}$ & $97.4^{c d}$ & $2.6^{a b c}$ & $4.4^{b}$ & $64.5^{e f}$ & $252^{a}$ & $98.0^{b c}$ & $2.0^{a b}$ \\
\hline Karima & $4.5^{a}$ & $52.4^{b c d}$ & $363^{d}$ & $97.2^{b c}$ & $2.6 \mathrm{a}^{b c d}$ & $3.4^{a b}$ & $48.3^{b c}$ & $395^{c}$ & $96.9^{a b}$ & $3.0^{b c}$ \\
\hline Oukrania & $5.3^{a}$ & $50.0^{a b}$ & $280^{a b}$ & $97.1^{a b c}$ & $2.7^{b c d e}$ & $4.2^{b}$ & $67.5^{f}$ & $321^{b}$ & $97.7^{b c}$ & $2.3^{a b}$ \\
\hline Peredovik & $5.1^{a}$ & $53.2^{c d}$ & $351^{c d}$ & $96.4^{a}$ & $3.4^{e}$ & $4.0^{b}$ & $62.1^{d e}$ & $348^{b c}$ & $97.2^{a b}$ & $2.8^{b c}$ \\
\hline Salima & $4.4^{a}$ & $53.0^{c d}$ & $338^{c d}$ & $96.6^{a b}$ & $3.2^{\text {cde }}$ & $3.6^{a b}$ & $45.7^{a b}$ & $336^{b c}$ & $98.0^{b c}$ & $2.0^{a b}$ \\
\hline Znatia & $4.7^{a}$ & $51.6^{a b c d}$ & $252^{a}$ & $97.4^{c d}$ & $2.4^{a b}$ & $4.5^{b}$ & $48.6^{b c}$ & $333^{b c}$ & $97.8^{b c}$ & $2.1^{a b}$ \\
\hline
\end{tabular}

${ }^{\mathrm{a}}$ Means within each column with different letters $(a-f)$ differ significantly $(P<0.05) ;{ }^{\mathrm{b}}$ Minor amounts of $\gamma$-tocopherol $(<1 \%)$ were also detected in most of the cultivars.

best oilseed-type cultivars were identified (e.g. B-107; Table 3), which suggests that a lower kernel tocopherol content is not an intrinsic property of confectionery-type cultivars and breeding for this trait could lead to confectionery-type cultivars with increased tocopherol content. There are no previous studies on the variation in tocopherol content of confectionery-type sunflower cultivars.

\subsection{Variation for phytosterol content}

The average kernel phytosterol content ranged from 2179 to $2883 \mathrm{mg} \mathrm{kg}^{-1}$ in plants grown in Spain and from 2398 to $3555 \mathrm{mg} \mathrm{kg}^{-1}$ in plants grown in Morocco (Table 4). No studies on variation in kernel phytosterol content in sunflower germplasm have been reported. In the extracted oil, phytosterol content ranged from 1800 to $4700 \mathrm{mg} \mathrm{kg}^{-1}$ oil in a large collection of sunflower germplasm (AyerdiGotor et al., 2007). Phytosterol content per kg oil in the cultivars used in the present study was calculated from the kernel phytosterol content (Table 4) and the kernel oil content (Table 3), which resulted in a range of variation from 4410 to 5502 $\mathrm{mg} \mathrm{kg}^{-1}$ oil in the plants grown in Spain and from 4142 to $7251 \mathrm{mg} \mathrm{kg}^{-1}$ oil in the plants grown in Morocco, though the final content in the extracted oil will depend upon the efficiency of the extraction process.

$\beta$-sitosterol was in all cases the predominant phytosterol, ranging from 54.0 to $60.6 \%$ of the total phytosterols in plants grown in Spain, and from 49.4 to $61.8 \%$ in plants grown in Morocco.
Other major phytosterols in all the cultivars were $\Delta^{7}$-stigmastenol (from 13.3 to $19.1 \%$ in Spain and from 13.9 to $26.9 \%$ in Morocco), campesterol (from 7.9 to $10.9 \%$ in Spain and from 5.5 to $10.1 \%$ in Morocco), stigmasterol (from 9.0 to $10.5 \%$ in Spain and from 7.5 to $9.9 \%$ in Morocco), and $\Delta^{7}$-avenasterol (from 2.8 to $4.2 \%$ in Spain and from 2.7 to $4.1 \%$ in Morocco) (Table 4). Other sterols detected in lower concentrations included $\Delta^{7}$-campesterol, clerosterol, $\Delta^{5}$-avenasterol, and $\Delta^{5,24}$-stigmastadienol. The phytosterol profile identified in the cultivars evaluated in the present study is similar to that reported for sunflower oil (Padley et al., 1994). The proportion of $\Delta^{7}$-stigmastenol in plants of cultivar B-96 grown in Morocco was particularly high $(26.9 \%)$, which should be explained on the basis of the strong genotype $\times$ location interaction identified for this trait (Table 2). Total phytosterol content in oilseed-type cultivars was significantly higher than that in confectionery-type cultivars both in Spain $(t=-2.2, P<0.01)$ and particularly in Morocco ( $t=-6.29 ; P<0.01)$, though confectionery-type cultivars with phytosterol content not significantly different from the best oilseed-type cultivars were found in both environments (B-96 and B-146 in Spain, B-2 in Morocco; Table 4). Therefore, breeding for increased phytosterol content in confectionerytype cultivars should be undertaken as a means to improve the nutritional value of seeds intended for food use. Differences in phytosterol profile between oilseed-type and confectionery-type cultivars were not consistent across environments. 
Table 4

Mean values for total kernel phytosterol content and proportion of individual phytosterols in 12 sunflower cultivars grown in Córdoba, Spain and AïnTaoujdate, Morocco in 2009

\begin{tabular}{|c|c|c|c|c|c|c|c|c|c|c|c|c|}
\hline \multirow[b]{2}{*}{ Cultivar } & \multicolumn{6}{|c|}{ Córdoba, Spain } & \multicolumn{6}{|c|}{ AÏN TAOUJDATE, MOROCCO } \\
\hline & $\begin{array}{c}\text { Total } \\
\text { sterols }^{\mathrm{a}} \\
\left(\mathrm{mg} \mathrm{kg}{ }^{-1}\right)\end{array}$ & Campesterol $^{b}$ & Stigmastenol & $\begin{array}{c}\beta= \\
\text { Sitosterol }\end{array}$ & $\begin{array}{c}\Delta^{7}- \\
\text { Stigmastenol }\end{array}$ & $\begin{array}{c}\Delta^{7} \text { - } \\
\text { Avenasterol }\end{array}$ & $\begin{array}{c}\text { Total } \\
\text { sterols } \\
\left(\mathrm{mg} \mathrm{kg}^{-1}\right)\end{array}$ & Campesterol & Stigmastenol & $\begin{array}{c}\beta= \\
\text { Sitosterol }\end{array}$ & $\begin{array}{c}\Delta^{7}- \\
\text { Stigmastenol }\end{array}$ & $\begin{array}{c}\Delta^{7} \text { - } \\
\text { Avenasterol }\end{array}$ \\
\hline B-2 & - & - & - & - & - & - & $3096^{\text {bcde }}$ & $8.9^{\text {cde }}$ & $8.5^{a b}$ & $57.4^{c}$ & $16.8^{b c d}$ & $3.4^{a b}$ \\
\hline B-96 & $2662^{b c}$ & $9.6^{b c d}$ & $9.6^{a b}$ & $60.6^{c}$ & $13.3^{a}$ & $2.8^{\mathrm{a}}$ & $2778^{a b c}$ & $5.5^{a}$ & $9.9^{b c}$ & $49.4^{a}$ & $26.9^{e}$ & $4.0^{b c}$ \\
\hline B-107 & $2369^{a b}$ & $10.7^{d}$ & $9.7^{a b}$ & $54.3^{a}$ & $16.3^{a b c}$ & $3.7^{b c}$ & $2398^{a}$ & $9.6^{d e}$ & $8.7^{a b}$ & $53.3^{b}$ & $18.9^{d}$ & $4.1^{c}$ \\
\hline B-132 & - & - & - & - & - & - & $2460^{a}$ & $10.1^{e}$ & $10.7^{c}$ & $56.96^{c}$ & $14.2^{a b}$ & $3.2^{a b}$ \\
\hline B-146 & $2819^{c}$ & $10.1^{c d}$ & $9.3^{a}$ & $58.2^{b c}$ & $15.2^{a b}$ & $2.9^{a}$ & - & - & - & - & - & - \\
\hline B-307 & $2179^{a}$ & $10.9^{d}$ & $9.3^{a}$ & $56.8^{a b}$ & $15.6^{a b}$ & $2.9^{a}$ & $2643^{a b}$ & $9.8^{d e}$ & $7.5^{\mathrm{a}}$ & $61.8^{d}$ & $13.9^{a}$ & $2.9^{a}$ \\
\hline MK-1 & $2827^{c}$ & $10.3^{c d}$ & $9.0^{a}$ & $56.8^{a b}$ & $15.9^{a b c}$ & $3.2^{a b}$ & $2850^{a b c}$ & $9.5^{d e}$ & $7.7^{a}$ & $60.3^{c d}$ & $15.6^{a b c}$ & $2.8^{a}$ \\
\hline Karima & $2575^{b c}$ & $8.5^{a b}$ & $10.5^{b}$ & $54.7^{a}$ & $17.9^{b c}$ & $3.7^{b c}$ & $3378^{d e}$ & $8.6^{b c d}$ & $8.3^{a}$ & $59.2^{c d}$ & $15.7^{a b c}$ & $3.4^{a b}$ \\
\hline Oukrania & $2751^{c}$ & $8.2^{a b}$ & $9.7^{a b}$ & $54.8^{a}$ & $17.6^{b c}$ & $4.2^{c}$ & $3360^{d e}$ & $8.0^{b c}$ & $9.1^{a b}$ & $59.0^{c d}$ & $15.35^{a b c}$ & $2.7^{a}$ \\
\hline Peredovik & $2587^{b c}$ & $9.1^{a b c}$ & $9.8^{a b}$ & $56.9^{a b}$ & $15.8^{a b c}$ & $3.3^{a b}$ & $3555^{e}$ & $9.0^{\text {cde }}$ & $8.7^{a b}$ & $59.2^{c d}$ & $14.5^{a b c}$ & $3.2^{a b}$ \\
\hline Salima & $2883^{c}$ & $8.7^{a b}$ & $9.8^{a b}$ & $54.8^{a}$ & $17.8^{b c}$ & $3.7^{b c}$ & $3009^{b c d}$ & $7.5^{b}$ & $7.8^{a}$ & $60.4^{c d}$ & $17.3^{c d}$ & $3.0^{a b}$ \\
\hline Znatia & $2773^{c}$ & $7.9^{a}$ & $9.9^{a b}$ & $54.0^{a}$ & $19.1^{c}$ & $4.2^{c}$ & $3208^{c d e}$ & $8.0^{b c}$ & $8.6^{a b}$ & $58.9^{c d}$ & $15.3^{a b c}$ & $3.7^{a b c}$ \\
\hline
\end{tabular}

${ }^{\mathrm{a}}$ Means within each column with different letters $(a-e)$ differ significantly $(P<0.05) ;{ }^{\mathrm{b}}$ Other sterols detected in lower concentrations included $\Delta^{7}$-Campesterol, Clerosterol, $\Delta^{5}$-Avenasterol, and $\Delta^{5,24}$-Stigmastadienol.

\subsection{Correlations between traits}

Some traits were correlated in one environment, but not in the other. In order to focus on consistent correlations, only those that were significant and in the same direction in both environments will be given in this section. Most of the correlations were observed between groups of related traits. Total tocopherol content was negatively correlated with the percentage of $\alpha$-tocopherol (Spain: $r=-0.56$; Morocco: $r=-0.27 ; P<0.01)$ and positively correlated with the percentage of $\beta$-tocopherol (Spain: $r=0.57$; Morocco: $r=0.27 ; P<0.01$ ). The percentages of both individual tocopherols showed a strong negative correlation (Spain: $r=-0.97$; Morocco: $r=-0.99 ; P<0.01$ ).

Total phytosterol content was not correlated with the percentage of individual phytosterols. Within the latter, two groups were observed. Campesterol and $\beta$-sitosterol content were positively correlated to each other and both of them negatively correlated with stigmasterol, $\Delta^{7}$-stigmastenol, and $\Delta^{7}$ avenasterol content (Table 5). Within the latter group, both $\Delta^{7}$ phytosterols were positively correlated to each other, whereas stigmasterol showed no consistent correlation with both $\Delta^{7}$ phytosterols.

Table 5

Correlation coefficients between individual phytosterols in 12 sunflower cultivars grown in Córdoba, Spain and AïnTaoujdate, Morocco in 2009

\begin{tabular}{|c|c|c|c|c|}
\hline & Campesterol & Stigmastenol & $\beta$-Sitosterol & $\Delta^{7}$-Stigmastenol \\
\hline \multicolumn{5}{|l|}{ Córdoba, Spain } \\
\hline Stigmastenol & -0.28 ** & & & \\
\hline$\beta$-Sitosterol & $0.35^{* *}$ & -0.30 ** & & \\
\hline$\Delta^{7}$-Stigmastenol & $-0.63^{* *}$ & $0.01 \mathrm{~ns}$ & -0.79 ** & \\
\hline$\Delta^{7}$-Avenasterol & $-0.42^{* *}$ & $0.46^{* *}$ & $-0.66^{* *}$ & $0.35^{\star \star}$ \\
\hline \multicolumn{5}{|c|}{ AïnTaoujdate, Morocco } \\
\hline Stigmastenol & $-0.24^{* *}$ & & & \\
\hline$\beta$-Sitosterol & 0.39 ** & $-0.45^{* \star}$ & & \\
\hline$\Delta^{7}$-Stigmastenol & -0.69 ** & $0.13 \mathrm{~ns}$ & $-0.77^{* *}$ & \\
\hline$\Delta^{7}$-Avenasterol & $-0.25^{\star \star}$ & $-0.02 \mathrm{~ns}$ & -0.59 ** & 0.36 ** \\
\hline
\end{tabular}

**, , , significant at the $1 \%$ and $5 \%$ probability levels, respectively; ns, not significant. 
Hundred-kernel weight was positively correlated with kernel oil content (Spain: $r=0.30, P<0.01$; Morocco: $r=0.17, \mathrm{P}<0.05)$. A positive correlation between thousand-seed weight and seed oil content based on intact sunflower achenes has been reported (Marinković, 1992). Hundred-kernel weight was also negatively correlated with total phytosterol content (Spain: $r=-0.61$; Morocco: $r=-0.36$; $\mathrm{P}<$ $0.01)$ and the concentrations of both $\Delta^{7}$-stigmastenol (Spain: $r=-0.31$; Morocco: $r=-0.45 ; \mathrm{P}<0.01$ ) and $\Delta^{7}$-avenasterol (Spain: $r=-0.51$; Morocco: $r=$ $-0.42 ; \mathrm{P}<0.01$ ), and positively correlated with the concentrations of campesterol (Spain: $r=0.39$; Morocco: $r=0.32 ; P<0.01$ ) and $\beta$-sitosterol (Spain: $r=0.40$; Morocco: $r=0.36$; $P<0.01$ ). No similar correlations between kernel weight and phytosterols have been reported previously.

\section{CONCLUSIONS}

The results of the present research reveal that sunflower cultivars used for the human food market contain large variations in kernel tocopherol and phytosterol content. Both types of cultivars did not differ for kernel weight, kernel oil content, tocopherol profile, or phytosterol profile. Conversely, oilseedtype cultivars had significantly higher average kernel tocopherol and phytosterol content than confectionery-type cultivars. However, confectionerytype cultivars with levels of tocopherols and phytosterols similar to the best oilseed-type cultivars were identified, which suggests that reduced levels of these compounds are not an intrinsic property of confectionery-type cultivars and they might be raised by conventional breeding.

\section{ACKNOWLEDGMENTS}

The research was partially supported by the Consejo Superior de Investigaciones Científicas (CSIC), Spain and Centre National pour la Recherche Scientifique et Technique (CNRST), Morocco, project number 2007MA0059.

\section{REFERENCES}

Ayerdi-Gotor A, Farkas E, Berger M, Labalette F, Centis S, Dayde J, Calmon A. 2007. Determination of tocopherols and phytosterols in sunflower seeds by NIR spectrometry. Eur. J. Lipid Sci. Technol. 109, 525-530.

Buendia MO, D'Appolonia BL. 1986. Storage studies on confectionery sunflower kernels. Cereal Chem. 63, 85-88.

El Asri M, Nabloussi A, Essahat A, El Fechtali M, Alghoum M. 2006. Enquête sur l'autoproduction des semences de tournesol et la collecte de populations locales au Maroc (zone du Gharb). Al Awamia 118/119, 86-102.

Fernández-Cuesta A, Aguirre-González MR, RuizMéndez MV, Velasco L. 2012. Validation of a method for the analysis of phytosterols in sunflower seeds. Eur. J. Lipid Sci. Technol. 114, 325-331.
Fernández-Martínez JM, Pérez-Vich B, Velasco L. 2009. Sunflower, in Vollmann J, Rajcan I (Eds.) Oil Crops. Springer, New York, pp. 155-232.

Goffman FD, Velasco L, Thies W. 1999. Quantitative determination of tocopherols in single seeds of rapeseed (Brassica napus L.). Fett/Lipid 101, 142145.

Izquierdo NG, Mascioli S, Aguirrezábal LAN, Nolasco SM. 2007. Temperature influence during seed filling on tocopherol concentration in a traditional sunflower hybrid. Grasas Aceites 58, 170-178.

Kaya Y. 2004. Confectionery sunflower production in Turkey, in Proc. 16th Int. Sunflower Conf., Fargo, ND, USA, pp. 817-822.

Lloyd-Williams F, Mwatsama M, Ireland R., Capewell S. 2008. Small changes in snacking behaviour: the potential impact on CVD mortality. Public Health Nutr. 12, 871-876.

Lofgren JR. 1997. Sunflower for confectionery food, bird food, and pet food, in Schneiter AA (Ed.) Sunflower Technology and Production. American Society of Agronomy, Madison, WI, USA, pp. 747-764.

Marinković R. 1992. Path-coefficient analysis of some yield components of sunflower (Helianthus annuus L.) Euphytica 60, 21-205.

Miller JF, Fick GN. 1997. The genetics of sunflower,in Schneiter (Ed.) Sunflower Technology and Production. American Society of Agronomy, Madison, WI, USA, pp. 441-495.

Nabloussi A, El Asri M, Akhtouch B, Gosset H, El Fechtali $M$, Alghoum $M$. 2005.Amélioration génétique du tournesol, in AbbadAndaloussi F, Chahbar A (Eds.) La Création Variétale à l'INRA: Méthodologie, Acquis et Perspectives. Institut Nationale de la Recherche Agronomique, Rabat, Morocco, pp. 237-252.

National Sunflower Association. 2011. Sunflower Statistics. World Supply and Disappearance. Retrieved December 30, 2011 from: http://www. sunflowernsa.com/stats/world-supply/.

Padley FB, Gunstone FD, Harwood JL. 1994. Occurrence and characteristics of oils and fats, in Gunstone FD, Harwood JL, Padley FB (Eds.) The Lipid Handbook. Chapman \& Hall, London, pp. 47-223.

Phillips KM, Ruggio DM, Ashraf-Khorassani M. 2005. Phytosterol composition of nuts and seeds commonly consumed in the United States. J. Agric. Food Chem. 53, 9436-9445.

U.S. Department of Agriculture. 2011. USDA National Nutrient Database for Standard Reference, Release 24. Retrieved December 30, 2011 from: http://www. ars.usda.gov/Services/docs.htm?docid = 8964 .

Velasco L, Fernández-Martínez JM, García-Ruiz R, Domínguez J. 2002. Genetic and environmental variation for tocopherol content and composition in sunflower commercial hybrids. J. Agric. Sci.139, 425429

Velasco L, Del Moral L, Pérez-Vich B, FernándezMartínez JM. 2010. Selection for contrasting seed tocopherol content in sunflower seeds. J. Agric. Sci. 148, 393-400.

Vlahakis C, Hazebroek J. 2000. Phytosterol accumulation in canola, sunflower, and soybean oils: effects of genetics, planting location, and temperature. J. Am. Oil Chem. Soc.77, 49-53.

Zhang H. 2004. Sunflower needed by the Chinese market, in Proc. 16th Int. Sunflower Conf., Fargo, ND, USA, pp. 823-826. 